\title{
Photocatalytical Degradation of Toluene and Cyclohexane Using LED Illumination
}

\author{
Joanna Mioduska*, Anna Zielińska-Jurek, Jan Hupka \\ Department of Chemical Technology, Faculty of Chemistry, Gdańsk University of Technology, \\ Narutowicza 11/12, 80-233 Gdańsk, Poland
}

Received: 14 June 2016

Accepted: 4 December 2016

\begin{abstract}
A sol-gel process followed by hydrothermal reaction was used to prepare coupled $\mathrm{WO}_{3}-\mathrm{TiO}_{2}$ photocatalysts with varying amounts of $\mathrm{WO}_{3}$ in respect to $\mathrm{TiO}_{2}$ ( $3 \mathrm{~mol} \%$ and $5 \mathrm{~mol} \%$ respectively). Additionally, photocatalysts have been subjected to different calcination temperatures of $400^{\circ} \mathrm{C}$ and $800^{\circ} \mathrm{C}$, which allowed us to compare how these affect photodegradation efficiency. Photocatalysts were characterized under a scanning electron microscope, $x$-ray diffraction, and by measuring BET surface area. Photocatalytic tests have been carried out following the degradation of toluene and cyclohexane in the gas phase under LED UV light $(375 \mathrm{~nm})$. Elevated calcination temperature turned to enhance photocatalytical efficiency of coupled $\mathrm{WO}_{3}-\mathrm{TiO}_{2}$ while degrading the model pollutant cyclohexane. It was demonstrated that light emitting diodes (LEDs) can be used effectively as a source of illumination in photoreactors, sufficient to obtain $90 \%$ compound elimination from the air during 15 minutes of illumination while applying a wellmatched photocatalyst.
\end{abstract}

Keywords: photocatalysis, titanium dioxide, tungsten trioxide, light emitting diodes (LEDs)

\section{Introduction}

Heterogeneous photocatalysis is highly appreciated for its removal of contaminants from both water and air, since under specific conditions hydroxyl radicals are formed with the ability to mineralize various pollutants. In order to be activated, titanium dioxide requires illumination with a proper wavelength of light, resulting in the promotion of an electron from the valence to the conduction band [1]. Photons with corresponding wavelengths are absorbed by a photocatalyst, resulting in the generation of electronhole pairs. This leads to separation of charge carriers and, consequently, to oxidation and reduction reactions on the surface of a semiconductor [2]. Titanium dioxide exists in three polymorphs: anatase, rutile, and brookite [3]; however, only the two first have value in photocatalysis. All crystalline phases of $\mathrm{TiO}_{2}$ are characterized with different energy band gaps, i.e., only a specific wavelength of light will activate anatase and rutile. The wavelength of radiation needed to induce excitation can be calculated from a quotient of Planck's constant $(\mathrm{h}=1240)$ and band gap width $\left(\mathrm{E}_{\mathrm{g}}\right)$. Anatase has a wider energy band gap of $3.2 \mathrm{eV}$, and thereby is activated under UV light. On the other hand, the rutile photoactivation energy band gap equals $2.8 \mathrm{eV}$, hence extends into the region of visible light. The disadvantage of rutile, when compared to anatase, refers to a higher recombination rate, which directly reflects on its lower photoefficiency [4].

*e-mail: joanna.mioduska@pg.gda.pl 
The principles and mechanism of photocatalysis have been widely discussed and presented in the literature [5]. However, this work considers the combined synergy of coupled semiconductors, namely titanium dioxide and tungsten trioxide. $\mathrm{WO}_{3}$ has its valence and conduction bands correspondingly lower than those of anatase (Fig. 1). The combination of these two semiconductors results in obtaining a composite with lower energy gap, hence with the activity shifted toward the visible region. Luo et al. [6] observed easier generation of electronhole pairs in a coupled $\mathrm{WO}_{3} / \mathrm{TiO}_{2}$ system in comparison with anatase or $\mathrm{WO}_{3}$. The photo-excitation mechanism of a coupled system is altered with respect to a single semiconductor. Illumination of coupled $\mathrm{WO}_{3} / \mathrm{TiO}_{2}$ results in the transfer of holes from the valence band of $\mathrm{WO}_{3}$ toward the valence band of $\mathrm{TiO}_{2}$, and transfers in the opposite direction of electrons from the $\mathrm{TiO}_{2}$ conduction band, which has more negative potential toward the $\mathrm{WO}_{3}$ conduction band [6]. Such conditions favour photocatalytical efficiency, since the recombination rate of electron-hole pairs that slows down and the production of $\mathrm{OH}$ radicals is enhanced [7].

Photocatalytical reactions are mainly carried out in photoreactors equipped with an artificial illumination source. The literature clearly distinguishes between photoreactors for aqueous or gas phases. Although the illumination can be periodic or continuous, the latest report by Tokodea O. et al. [8] shows that the use of controlled periodic illumination (CPI) for photocatalysis is not necessarily advantageous. Besides solar light (possessing a broad spectrum of radiation, mainly in the range of visible light), conventional UV lamps (xenon, fluorescent, halogen, metal halide, or mercury) make the illumination source in laboratory photoreactors. Until recently, there was only a small selection of monochromatic light sources that could be applied effectively in photocatalysis. In the last few years, a new type of light source has appeared: light-emitting diodes (LEDs). LEDs that are able to continuously emit light in the UV range are of particular interest.

The first reports of LED application in photoreactors appeared in 2005, when Carmignani et al. [9] received a patent on a method for purifying gaseous pollutants by means of photocatalysis that utilizing LED as a source of light. LEDs represent a relatively new source of light

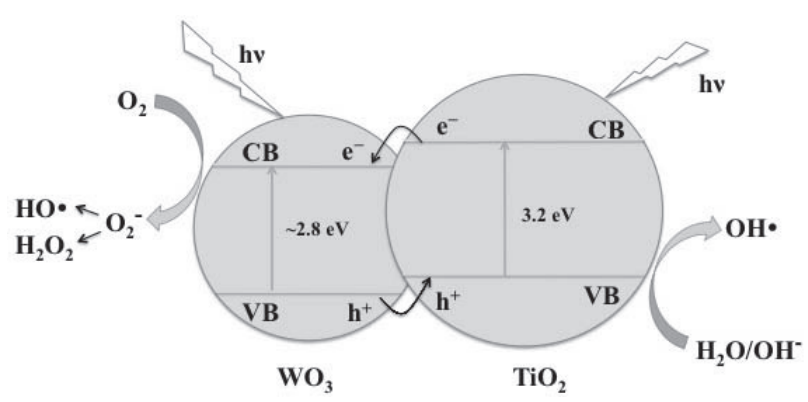

Fig. 1. Mechanism of photoexcitation of coupled $\mathrm{WO}_{3} / \mathrm{TiO}_{2}$ $\mathrm{CB}$ - conduction band, $\mathrm{VB}$ - valance band, according to [6]. used in photoreactors, since conventional illumination is still more frequently used in research. Therefore, LED applicability requires confirmation with further studies on selected pollutants. In this regard, we investigated the efficiency of toluene and cyclohexane removal in an LED $\mathrm{TiO}_{2}$-based photocatalyst system.

The photocatalytic degradation of hydrocarbon vapours using commercial $\mathrm{TiO}_{2}$ photocatalyst has been extensively studied [10-11]. Toluene is very often chosen as a model pollutant in photocatalytical processes, which is very advantageous in terms of comparing obtained results. The photodegradation efficiency of toluene in the presence of titania-based photocatalysts may even reach $100 \%$ [12-13]. Toluene is one of the typical indoor volatile organic compounds, as well as a member of the BTEX group. It can be found in everyday products such as paints, lacquers, inks, adhesives, cosmetics, and gasoline, but unfortunately toluene can cause adverse health effects. Breathing its vapours can result in headache and irritation of eyes, nose, or skin, but also disorders of the central nervous system or liver and kidney damage. According to the U.S. Occupational Safety and Health Administration (OSHA), the permissible time-weighted average (TWA) exposure limit of toluene is $200 \mathrm{ppm}$.

A compound that is less frequently chosen as a model pollutant in photocatalytical reactions, but also is hazardous, is cyclohexane. Cyclohexane belongs to hydrocarbons, which are determined in the air at workplaces. According to OSHA, the permissible exposure limit for cyclohexane is $300 \mathrm{ppm}$. Poisoning may cause a range of negative symptoms, including anxiety, throat and eye irritation, dizziness and nausea, toxicity of the central nervous system, respiratory failure, and narcosis. Cyclohexane vapours form explosive mixtures with air. They are more dense than air and tend to accumulate near ground and in the lower parts of rooms. The explosive limit for cyclohexane is relatively low, in the range of $1.2-4.8 \%$. Cyclohexane manufacturing plants use condensers to limit vapour emissions to the atmosphere. In the case of cyclohexane leakage to the air it is important to quickly degrade target pollutants. Zheng et al. [14] carried out an experiment on photodegradation efficiency of gas-phase cyclohexane in the presence of various $\mathrm{TiO}_{2}$ nanostructures. The results demonstrate that titania-based photocatalysts can oxidize gaseous cyclohexane within 6 hours, with $96 \%$ degradation efficiency.

Our aim was to verify LED illumination for degradation of selected hydrocarbons - namely cyclohexane and toluene. LED construction allows for emitting most of its power within the desired wavelength. LEDs have an opportunity to become more popular over conventional light sources, because while having the potential for almost the same applications, they are also supposed to be more economical. LEDs can be successfully applied in photocatalysis because they have monochromatic light [15]. They may consist of III-nitride, including gallium nitride $(\mathrm{GaN})$, indium gallium nitride $(\mathrm{InGaN})$, aluminium gallium nitride $(\mathrm{AlGaN})$, or aluminum nitride (AlN) [16]. InGaN LEDs can emit a wide spectrum of light, from UV 
to IR. By changing the indium fraction in the active layers of InGaN, the specific wavelength spectra can be obtained [17]. It is desired that the wavelength would be optimal for the photocatalytic process, and consequently LEDs could serve as a more efficient and energy-safe source of illumination than lamps with a more flat spectrum. Another advantage of LEDs is that they are a discrete source of light and thus are easier to be built-in in photoreactors.

\section{Materials and Methods}

All applied reagents were of analytical grade and used without further purification. Titanium-based photocatalysts were prepared by the sol-gel method using titanium tertbutyl oxide as a precursor (TBT $\geq 97 \%$, supplied by Fluka). While the solution was thoroughly mixed, we added ammonium para-tungstate (ApT, 99.99\%) - a precursor of tungsten trioxide - or pure tungsten trioxide (99.99\%) from Sigma-Aldrich to the solution. The amount of ammonium paratungstate or pure $\mathrm{WO}_{3}$ used in the preparation step was calculated on the assumption that the content of $\mathrm{WO}_{3}$ in the photocatalysts after synthesis should be equal to 3 or $5 \mathrm{~mol} \%$ of the photocatalyst dry mass. After thorough stirring the solution was transferred to a hydrothermal reactor. Next, it was centrifuged, dried, and calcined at $400^{\circ} \mathrm{C}$ or $800^{\circ} \mathrm{C}$. A more detailed account of this procedure can be found elsewhere [18]. The samples were chosen based on earlier data regarding process parameters and characterization of photocatalysts done by Mioduska et al. [18]. In the cited paper, although pertaining to the aqueous phase, photocatalysts calcined at $800^{\circ} \mathrm{C}$ were characterized with enhanced photodegradation efficiency compared with those calcined at lower temperatures. An increase in calcination temperature above $400^{\circ} \mathrm{C}$ resulted in favorable reduction of the amorphous phase in the coupled $\mathrm{WO}_{3}-\mathrm{TiO}_{2}$ photocatalyst. Photocatalysts calcined at $400^{\circ} \mathrm{C}$ were also chosen, since it is a very common temperature described in the relevant literature and may be a reference.

The specific surface area was determined by the multipoint Brunauer-Emmett-Teller (BET) method by liquid nitrogen adsorption at $77 \mathrm{~K}$ on a Micromeritics Gemini V. Emission scanning electron microscope (FEI Quanta FEG 250) with ET secondary electron detector that we used to study surface morphology of coupled $\mathrm{WO}_{3}-\mathrm{TiO}_{2}$ photocatalysts. Beam accelerating voltage was maintained at $10 \mathrm{kV}$. The structure of catalysts was also characterized by X-ray diffraction technique (XRD) using a Rigaku MiniFlex with $\mathrm{Cu}-\mathrm{K} \alpha 2$ radiation.

The photocatalytic activity of prepared photocatalysts was evaluated with respect to the degradation of toluene and cyclohexane vapours, with initial concentration at 200 and $150 \mathrm{ppm}$, respectively. The samples were irradiated with an array of 25 UV LEDs characterized with $\lambda_{\text {max }}$ equal to $375 \mathrm{~nm}$ (Liteon Optoelectronics through-hole lamp, LTL2V3TU75K). The photocatalyst was coated onto a glass plate and mounted in a $30 \mathrm{~cm}^{3}$ reaction cell (stainless steel flat, circular reactor). Illumination was external through a quartz wall. After closing the reactor, either toluene or cyclohexane were passed through the reactor for 1 minute, a blind sample was taken, and the illumination was switched on for 15 minutes. During that time probes were taken every 5 minutes and analysed for cyclohexane or toluene in a gas chromatograph (PerkinElmer, model Clarus 500, fused silica capillary column Elite-5 with 5\% diphenyl and 95\% dimethyl polysiloxane stationary phase). Gas samples were analyzed for primary contaminants (i.e. cyclohexane or toluene). The results are provided in terms of cyclohexane/toluene conversion, defined as:

$$
\begin{gathered}
\% \text { cyclohexane/toluene conversion } \\
=\left(\mathrm{C}_{0}-\mathrm{C}\right) / \mathrm{C}_{0} \times 100
\end{gathered}
$$

...where $C_{0}$ is influent hydrocarbon concentration and $C$ is effluent hydrocarbon concentration at any given time.

\section{Results and Discussion}

Four experiments on two different model pollutants were carried out to determine whether the LEDphotocatalyst system has the potential to degrade organic compounds. The results are presented in Table 1. Fig. 2 graphically presents the photodegradation of cyclohexane and toluene under UV LED light $\left(\lambda_{\max }=375 \mathrm{~nm}\right)$ in the presence of $3 \mathrm{~mol} \% \mathrm{WO}_{3}-\mathrm{TiO}_{2}$ and $5 \mathrm{~mol} \%$ $\mathrm{WO}_{3}-\mathrm{TiO}_{2}$ photocatalysts, respectively, calcined at $400^{\circ} \mathrm{C}$ and $800^{\circ} \mathrm{C}$. Results presented in Table 1 show that the heat treatment of a photocatalyst had less influence on the photodegradation efficiency in the case of toluene.

Table 1. Degradation efficiency of coupled $\mathrm{WO}_{3}-\mathrm{TiO}_{2}$ photocatalysts after 15 -minute illumination with $375 \mathrm{~nm} \mathrm{LEDs}$ and $62 \mathrm{~W} / \mathrm{m}^{2}$ average power flux.

\begin{tabular}{|c|c|c|c|c|}
\hline Photocatalyst & Target pollutant & $\begin{array}{c}\text { Photocatalyst } \\
\text { calcination } \\
\text { temperature }\left({ }^{\circ} \mathrm{C}\right)\end{array}$ & $\begin{array}{c}\text { Elimination } \\
(\%)\end{array}$ & $\begin{array}{c}\text { Specific surface area } \\
\text { BET } \\
\left(\mathrm{m}^{2} / \mathrm{g}\right)\end{array}$ \\
\hline $3 \mathrm{~mol} \% \mathrm{WO}_{3}-\mathrm{TiO}_{2}$ & cyclohexane & 400 & 70 & 134 \\
\hline $3 \mathrm{~mol} \% \mathrm{WO}_{3}-\mathrm{TiO}_{2}$ & cyclohexane & 800 & 80 & 6 \\
\hline $5 \mathrm{~mol} \% \mathrm{WO}_{3}-\mathrm{TiO}_{2}$ & toluene & 400 & 78 & 183 \\
\hline $5 \mathrm{~mol}_{2} \mathrm{WO}_{3}-\mathrm{TiO}_{2}$ & toluene & 800 & 5 \\
\hline
\end{tabular}




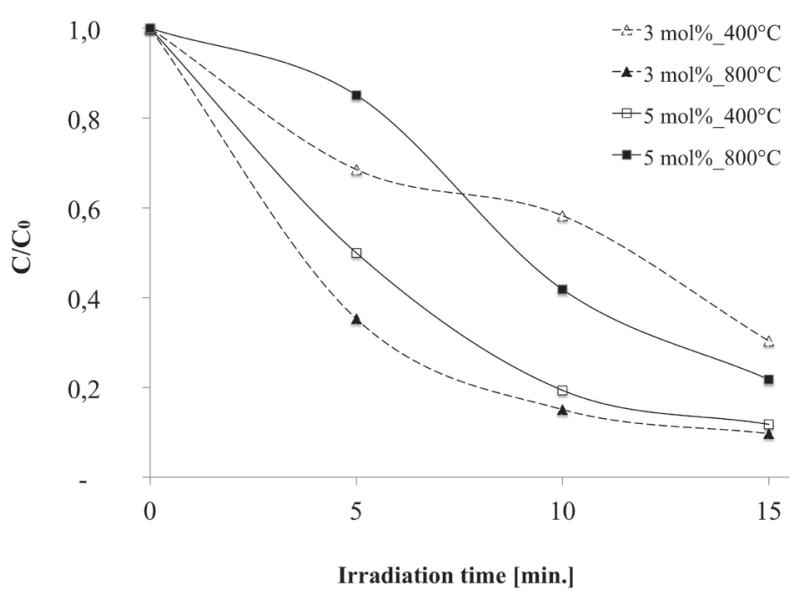

Fig. 2. Photodegradation of cyclohexane and toluene under UV LED light $\left(\lambda_{\max ^{-}}=375 \mathrm{~nm}\right)$ in the presence of $3 \mathrm{~mol} \%$ $\mathrm{WO}_{3}-\mathrm{TiO}_{2}$ and $5 \mathrm{~mol} \% \mathrm{WO}_{3}-\mathrm{TiO}_{2}$ photocatalysts, respectively, calcined at $400^{\circ} \mathrm{C}$ and $800^{\circ} \mathrm{C}$.

The amount of cyclohexane was easier decreased in the presence of $3 \mathrm{~mol} \% \mathrm{WO}_{3}-\mathrm{TiO}_{2}$ calcined at $800^{\circ} \mathrm{C}$ than at $400^{\circ} \mathrm{C}$. In order to find the cause for that result, we additionally determined the BET surface area for coupled $\mathrm{WO}_{3}-\mathrm{TiO}_{2}$ photocatalysts. We observed a significant decrease in the value for photocatalysts calcined at $800^{\circ} \mathrm{C}$, which was around 23 to 36 times smaller than the surface area of the photocatalyst for $3 \mathrm{~mol}^{\circ} \mathrm{WO}_{3}$ $\mathrm{TiO}_{2}$ and for $5 \mathrm{~mol} \% \mathrm{WO}_{3}-\mathrm{TiO}_{2}$, respectively, calcined at $400^{\circ} \mathrm{C}$. Sintering of grains might have caused such a reduction.

Although photocatalysts with smaller BET surface area are expected to be less effective in degradation of target pollutants, the experiments showed the opposite. The increase in calcination temperature resulted in the formation of active crystal phase of anatase as well as the

a)

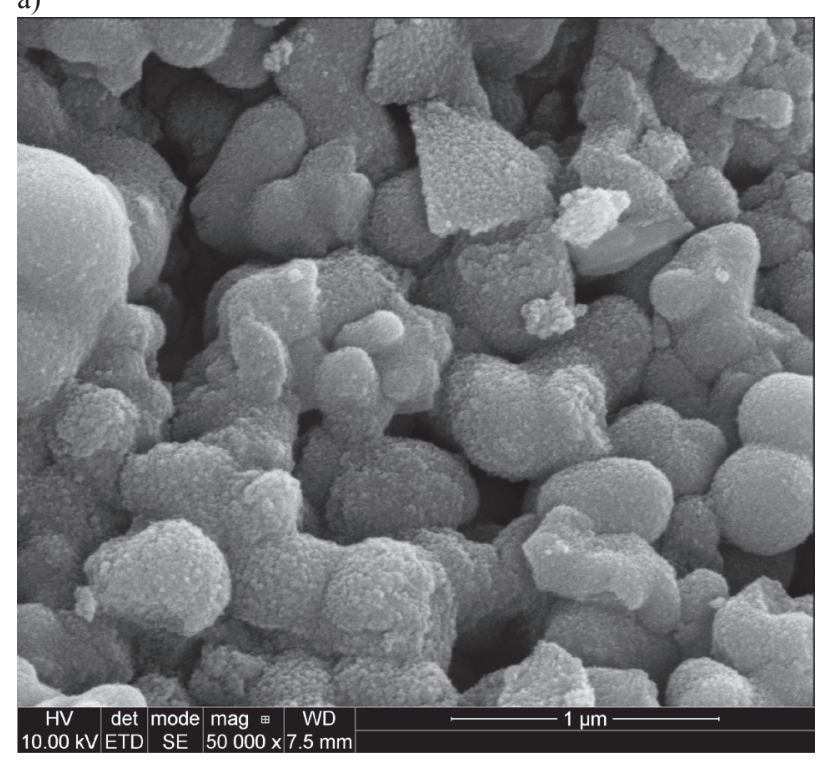

rutile phase. According to Długosz et al. [19], the mixture of anatase and rutile exhibited higher photocatalytic efficiency because of one-way electron transfer from the anatase conduction band to the rutile conduction band, allowing for more efficient electron hole charge separation. Both our photocatalysts had very high activity when calcined at elevated temperatures, which is typical for the coexistence of anatase and rutile phases. This explains that the high surface area cannot by itself determine degradation efficiency. Too much developed surface area may also promote the adsorption of impurities at the surface, thus reducing photocatalytic activity.

SEM images were also created in order to determine the difference in morphology that might have influenced the photoactivity of the samles. Coupled $\mathrm{WO}_{3}-\mathrm{TiO}_{2}$ photocatalysts were selected for microscopic analysis, having the same composition $\left(5 \mathrm{~mol} \% \mathrm{WO}_{3}\right.$ in respect to $\mathrm{TiO}_{2}$ ), but calcined at $400^{\circ} \mathrm{C}$ and $800^{\circ} \mathrm{C}$ (Fig. 3). Both samples are characterized with spherical particles. The inverse relationship between particle size and BET surface area was observed. Comparing Fig. 3a) with 3b) we can see that the size of particles is influenced by the heat treatment process. Photocatalysts calcined at $800^{\circ} \mathrm{C}$ have bigger nanoparticles compared to those calcined at $400^{\circ} \mathrm{C}$.

The XRD patterns of coupled $5 \mathrm{~mol} \% \mathrm{WO}_{3}-\mathrm{TiO}_{2}$ composite confirmed that the photocatalyst calcined at $400^{\circ} \mathrm{C}$ consisted solely of anatase, while an increase in temperature to $800^{\circ} \mathrm{C}$ resulted in partial phase transformation from anatase to rutile $(80 \%$ to $20 \%$, respectively). In both samples only the monoclinic phase of tungsten trioxide was observed. Prepared powders were nanocrystalline regardless of the value of calcination temperature.

Experiments presented in the relevant literature usually applied monochromatic lamps with $254 \mathrm{~nm}$ for toluene removal [12, 20-21]. The power flux varies depending on the construction of a photoreactor, and is

b)

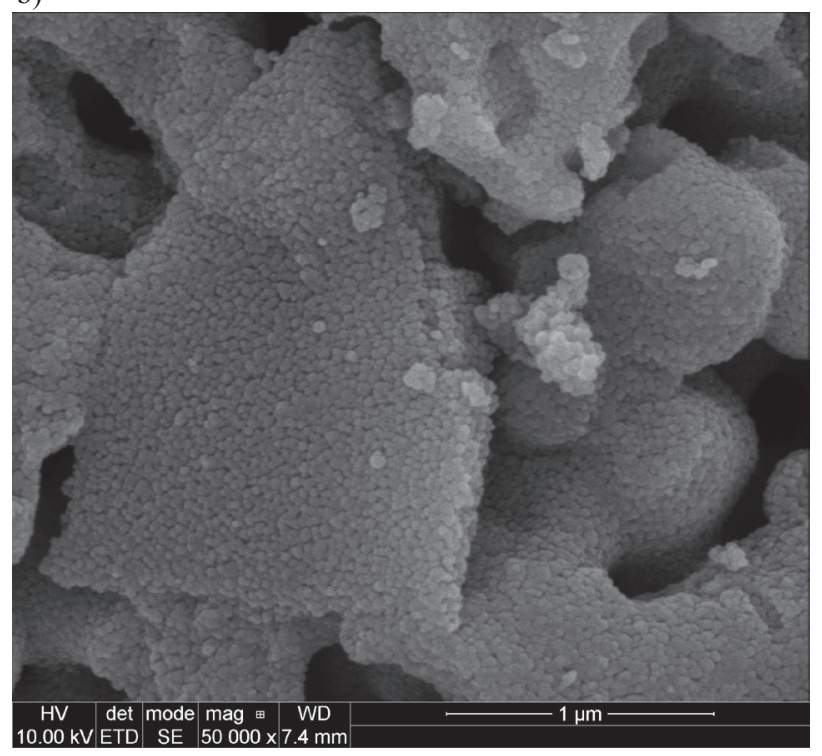

Fig. 3. SEM images for samples $5 \mathrm{~mol}^{\circ} \mathrm{WO}_{3}-\mathrm{TiO}_{2}$ calcined at a) $400^{\circ} \mathrm{C}$ and b) $800^{\circ} \mathrm{C}$. 
not always specified. Keshmiri et al. [20] examined the photoca-talytical oxidation of toluene. They carried out expe-riments with two UV lamps with higher intensity of $254 \mathrm{~nm}$ and $365 \mathrm{~nm}$, having different power flux equal to $30 \mathrm{~W} / \mathrm{m}^{2}$ and $21 \mathrm{~W} / \mathrm{m}^{2}$, respectively, and observed that illumination with $254 \mathrm{~nm}$ provided a better photocatalytic oxidation rate of toluene (up to $3.9 \mathrm{~g} / \mathrm{m}^{2} / \mathrm{h}$ ). Lamp intensity was indicated as the primary reason for better photodegradation. Similar conclusions were drawn by Kim et al. [22], who investigated the effect of total irradiation on the photo-oxidation process of cyanide and stated that the removal efficiency is clearly linked with applied light intensity. Although the LEDs used in our experiments were of quite low energy $\left(\lambda_{\max }=375 \mathrm{~nm}\right)$, they secured an average light intensity of $62 \mathrm{~W} / \mathrm{m}^{2}$. Ten minutes of irradiation resulted in clear concentration drop of analysed model pollutants in the presence of coupled $\mathrm{WO}_{3}-\mathrm{TiO}_{2}$ photocatalysts (Fig. 2). The degradation rate of cyclohexane was faster in the presence of photocatalysts calcined at $800^{\circ} \mathrm{C}$ ( $3 \mathrm{~mol} \% \mathrm{WO}_{3}-\mathrm{TiO}_{2}$ ), and a similar degradation rate was observed for $5 \mathrm{~mol} \% \mathrm{WO}_{3}-\mathrm{TiO}_{2}$ calcined at $400^{\circ} \mathrm{C}$ in toluene removal. Total removal was not observed, although in both cases 15 minutes of irradiation resulted in degradation of around $90 \%$ of target pollutants. We should also emphasize that despite the calcination temperature and the type of model pollutant, in the presence of coupled $\mathrm{WO}_{3}-\mathrm{TiO}_{2}$ photocatalysts and relatively short illumination time with UV LEDs we obtained a high degradation level. Kim et al. [22] not only emphasized the importance of irradiation, but also drew attention to the high removal efficiency of LEDs as a source of light, with respect to consumption of electrical energy. Our experiments effectively used LEDs as a source of illumination and confirmed that LED illumination can be successfully used in photocatalytical degradation of tolunene or cyclohexane.

\section{Conclusions}

The correlation of obtained results of BET surface area, particle size, and shape determined under a scanning electron microscope, as well as XRD difractograms indicating crystalline phase, does not directly translate into photocatalytical efficiency in degradation of different model pollutants, namely cyclohexane and toluene. However, a comparison of the results shows that the calcination temperature of the prepared photocatalysts significantly affected the efficiency of degradation. Photocatalysts calcined at $800^{\circ} \mathrm{C}$ were more effective than those calcined at $400^{\circ} \mathrm{C}$ regarding the removal of cyclohexane. Much less data is specified with respect to the gas phase, and thus it is more difficult to compare obtained results with those presented in relevant literature. Research incorporating varying process conditions, wavelength, power flux, and illumination time is on its way in order to verify if LEDs, especially UV-LEDs, can serve as a better light source in gas photoreactors, and also to confirm that while having lower power consumption one can obtain at least similar degradation rates.

\section{Acknowledgements}

The authors wish to thank the National Centre for Research and Development in Poland, Grant No. BG1/ EKOŁUPKI/13 for the financial support provided for this research.

The authors acknowledge Jakub Karczewski, PhD, from the Faculty of Applied Physics and Mathematics, Gdansk University of Technology, for making SEM photographs of the $\mathrm{WO}_{3}-\mathrm{TiO}_{2}$ photocatalysts.

\section{References}

1. PERKOWSKI J., BZDON S., BULSKA A., JÓŹWIAK W.K., Decomposition of Detergents Present in Car-Wash Sewage by Titania Photo-Assisted Oxidation, Polish Journal of Environmental Studies, 15 (3) 457, 2016

2. PAWAR R.C., LEE C.S., Heterogeneous NanocompositePhotocatalysis for Water Purifiacation, Chapter 1 - Basics of Photocatalysis, Micro \& Nano Technologies Series, William Andrew Applied Science Publishers, USA, NY, 2015

3. ESCH T.R., GADACZEK I., BREDOW T., Surface structures and thermodynamics of low-index of rutile,brookite and anatase - A comparative DFT study, Applied Surface Science 288, 275, 2014

4. LI G., CHEN L., GRAHAM M.E., GRAY K.A., A comparison of mixed phase titania photocatalysts prepared by physical and chemical methods: The importance of the solid-solid interface, Journal of Molecular Catalysis A: Chemical 275, 30,2007

5. SOBCZYŃSKI A., DOBOSZ A., Water Purification by Photocatalysis on Semiconductors, Polish Journal of Environmental Studies, 10 (4), 195, 2001

6. LUO X., LIU F., LI X., GAO H., LIU G., $\mathrm{WO}_{3} / \mathrm{TiO}_{2}$ nanocomposites: Salt-ultrasonic assisted hydrothermal synthesis and enhanced photocatalytic activity, Materials Science in Semiconductor Processing 16, 1613, 2013

7. ARUTANTI O., NANDIYANTO A.B.D., OGI T., ISKANDAR F., KIM T.O., OKUYAMA K., Synthesis of composite $\mathrm{WO}_{3} / \mathrm{TiO}_{2}$ nanoparticles by flame-assisted spray pyrolysis and their photocatalytic activity, Journal of Alloys and Compounds 591, 121, 2014

8. TOKODEA O., PRABHUB R., LAWTONC L.A., ROBERTSOND P.K.J., Controlled periodic illumination in semiconductor photocatalysis, Journal of Photochemistry and Photobiology A: Chemistry 319-320, 96, 2016

9. CARMIGNANI G., FREDERICK L., SITKIEWITZ S., Apparatus and method for photocatalytic purification and disinfection of fluids, US Patent, US 6902653 B2, issued 2005

10. MO J., ZHANG Y., XU Q., LAMSON J.J., ZHAO R., Photocatalytic purification of volatile organic compounds in indoor air: A literature review, Atmospheric Environment 43, 2229, 2009

11. KAMAL M.S., RAZZAK S.A., HOSSAIN M.M., Catalytic oxidation of volatile organic compounds (VOCs). A review, Atmospheric Environment 140, 117, 2016

12. BOUZAZA A., LAPLANCHE A., Photocatalytic degradation of toluene in the gas phase: comparative study of some 
TiO supports, Journal of Photochemistry and Photobiology A: Chemistry 150, 207, 2002

13. VERBRUGGENA S.W., $\mathrm{TiO}_{2}$ photocatalysis for the degradation of pollutants in gas phase: From morphological design to plasmonic enhancement, Journal of Photochemistry and Photobiology C: Photochemistry Reviews 24, 64, 2015

14. ZHENG C., LI X., ZHAO Q., QU Z., QUAN X., Photo-oxidation of gas-phase cyclohexane species over nanostructured $\mathrm{TiO}_{2}$ fabricated by different strategies, Separation and Purification Technology 67, 326, 2009

15. JO W.K., KANG H.J., LED Irradiation of a Photocatalyst for Benzene, Toluene, Ethyl benzene, and Xylene Decomposition, Chinese Journal of Catalysis, 33 (9-10), 1672, 2012

16. SONG K., MOHSENI M., TAGHIPOUR F., Application of ultraviolet light-emitting diodes (UV-LEDs) for water disinfection: A review, Water Research 94, 341, 2016

17. TSAI S.-C., FANG H.-C., LAI Y.-L., LU C.-H., LIU C.P., Efficiency enhancement of green light emitting diodes by improving the uniformity of embedded quantum dots in multiple quantum wells through working pressure control, Journal of Alloys and Compounds, 669, 156, 2016.
18. MIODUSKA J., ZIELINSKA-JUREK A., HUPKA J., JANCZAREK M., The effect of calcination temperature on structure and photocatalytic properties of $\mathrm{WO}_{3} / \mathrm{TiO}_{2}$ nanocomposites, Journal of Nanomaterials 2016, doi:10.1155/2016/3145912

19. DŁUGOSZ M., WAŚ J., SZCZUBIAŁKA K., NOWAKOWSKA M., $\mathrm{TiO}_{2}$-coated EP as a floating photocatalyst for water purification, Journal of Materials Chemistry A 2, 6931, 2014

20. KESHMIRI M., TROCZYNSKI T., MOHSENI M., Oxidation of gas phase trichloroethylene and toluene using composite sol-gel $\mathrm{TiO}_{2}$ photocatalytic coatings, Journal of Hazardous Materials 128, 130, 2006

21. HUANG H., LI W., Destruction of toluene by ozone-enhanced photocatalysis: Performance and mechanism, Applied Catalysis B: Environmental 102, 449, 2011

22. KIM S.H., LEE S.W., LEE G.M., LEE B.-T., YUN S.-T., KIM S.-O., Monitoring of $\mathrm{TiO}_{2}$-catalytic UV-LED photo-oxidation of cyanide contained in mine wastewater and leachate, Chemosphere 143, 106, 2016. 